\title{
Outlook: What is the Business Value of Ethical Tech?
}

\author{
In our Outlook section we ask a cross-disciplinary range of experts to answer important ques- \\ tions on how emerging technology will impact society. Each contributor will provide their \\ unique perspective on a particular issue thereby generating novel and important insights. \\ In this edition we ask: What is the business value of ethical tech?
}

\section{Steffen Augsberg}

Professor of Public Law at the Justus-Liebig-Universität Gießen, German Ethics Council

The digital transformation has captured and changed our informational assumptions and relationships. Specific problems are associated with this process (such as a new potential for exclusionary and discriminatory practices). At the same time, it does imply improved possibilities for individual orientation and information. In particular, with regard to customer relationship aspects, increased curiosity and greater knowledge on the part of customers is to be expected. Here, the perceptible trend towards social responsibility has a strengthening effect. People do not yet behave in all areas of life in the way they consider normatively appropriate. However, the pressure to justify one's actions is clearly rising. This can be seen with particular clarity in the example of climate change: many still drive an SUV, fly to their holiday destinations and eat meat. But they are doing this with an increasingly bad conscience, and they are asking what possibilities there are to 'balance the books' - how much BBQ meat am I allowed to eat if I voted 'green' in the European elections? Moreover, the moral sensitisation can be observed beyond these special circumstances: For instance, people are questioning which consequences arise from a business model, whether a product bears intolerable risks for workers and/or the environment or whether less data-intensive procedures are possible.

Thus, ethical tech can be understood first and foremost as an anticipatory reaction to the social changes described. Taking ethical concerns into account at the early stages of developing and designing a product or a service enables entrepreneurs to use this consideration for self-marketing at a later stage. This might prove advantageous especially compared to competi- tors who do not exhibit this extrinsically motivated sensitivity. It can also help to attract employees who not only pay attention to their own work life balance, but also place a premium on an ethically acceptable employer.

\section{Siri Beerends}

Cultural Sociologist, Writer and Researcher at medialab SETUP, PhD Candidate at the University of Twente

Business value can be about market value, investment value, societal value or other forms of value. In an ideal world, developing ethical technologies would benefit all forms of business value. Unfortunately, in a capitalistic system it doesn't work that way. We see this with companies like Google and Facebook where market value does not serve values like privacy and autonomy. Nevertheless, with the increasing criticism of 'Big Tech', I think businesses might gain commercial profit from ethical alternatives to existing models.

However, ethical technology should not be about business value but about planet value. Although companies are shouting 'people and planet over profit', we are still living in a world where business value and planet value often don't converge. Ethical technology has become such a hyped term that it suffers from inflation. Many companies use the term and ethical boards as a tool for getting around regulation. This results in 'ethics washing' or 'ethics theatre': a facade of concern for the greater good, engineered to repress criticism and keep public attention away from the real problems.

DOI: 10.21552/delphi/2019/2/7 
Also, there is no consensus on what ethical technology is, resulting in ethical principles that are too vague to be effective. When we look for example at 'ethical AI-systems', it is impossible to implement ethical decision making in the ambiguous, organic and fluid way humans apply it. Ethical values differ between cultures, countries and income levels; they are not universal, static and coherent. In everyday life, ethical decisions take place in a particular situation with particular dynamics, (un)intentions, context-dependent factors and irrational aspects. Who gets to decide which moral rules and variables are general enough to encode? I'm not saying that we shouldn't, I'm saying that AI changes the way we apply ethics. It will become more rigid; more black and white because AI-systems cannot detect and take into account human (un)intentions when they calculate a particular decision.

\section{Paul Nemitz}

Principal Advisor at DG Justice, European Commission

Soon we will see investment vehicles focused on ethical tech. These funds will follow the examples of green funds, which only invest in environmentally sustainable projects and companies, but their focus will be technology and business models which are hyper compliant with GDPR and still very data intensive. In the same way that there is a lot of money to be made with clean technology, because it is more resource efficient, thus saving costs, more sympathetic, and more sustainable, ethical tech reduces risks to investors and will be easier to market. There are a number of reasons why Apple's success on the stock exchange is lasting so long. One is that Apple is actively seeking to manage personal data in a way that reduces risks to the company and customers. With tech accountability journalism and whistle blower protection gaining ground, and Facebook expecting to be fined billions for privacy breaches, the risks of those making profits in the grey zone of ethics, the shadow of half lies and half-truth, is rising on both sides of the Atlantic. Sustainable profits require credibility and trust with customers and stakeholders. This is what investments in looking out for rights of individuals, democracy and the rule of law from the outset of tech and business model development brings to the mark, in addition to safety and sustainability.

\section{Ida Rust}

Consultant Strategy \& Policy in Innovation, Advisor Human Factors \& AI, PhD Student at the University of Twente

Ethics deals with questions about right behaviour. Ethical tech is technology that behaves according to what we have decided is right. The urgency of a debate on ethical tech is due to the increase in the utilisation of (autonomous) complex decision making technology. Examples of emerging tech that prompt ethical questions are: does an autonomous military drone act justly, when it exterminates a family to prevent the husband from carrying out terrorist activities, potentially causing a multitude of victims? Is a company allowed to use data about children's behaviour retrieved from a kid's toy for commercial purposes? Should we censor social networks to protect users from adverse information? The difference with previous technology is that emerging technology seems to be more radically embedded in human life - but is there really a difference when it comes to the business value?

The goal of business is to make money under the condition of the existence of a profitable market, regardless of the ethical status of the traded good: eg the sales of pricier organic food are flourishing; vehicle manufacturers are switching to the production of electric cars; the monetary value of Bitcoin is astronomical, while the driver behind the development of crypto-currencies is the creation of an honest and transparent transaction system. As long as there is demand, there is business potential. Ethical tech is not an exception. Therefore, it is just a matter of time before a smart phone, self-driving car or credit bank carries the label 'Ethically Approved'. Like my shampoo that says 'Cruelty Free'.

The viability of a company doesn't solely depend on its economic value. Nevertheless, I consider it more urgent to ask if and how we should interfere in the market to guarantee human beneficial technology.

\section{Nicholas Borsotto}

\section{Founder at Archgriffin Consulting}

Often people assume that pushing for ethics in the Tech requires forgoing 'selfish' business goals, but 
that doesn't have to be the case. To invest in ethical Tech means to hold your products and practices to a clear set of values, often related to transparency, privacy, consent, bias and the overall impact of your product in the wider society, may those be users, customers or neither. To do so might hit your profits in the short run, but in the long term, they can become real competitive advantages, for example:

- Customer Loyalty \& Branding: Today, millions worry about ethical issues, such as privacy, consent, and participation in unwitting AI experiments. They have good reason to do so as there is an opportunity to differentiate itself from the rest, to be a champion of user rights deserving of their trust.

- Hiring: In the competitive world of recruiting top tech talent, often a decision comes down to factors beyond salary. Caring about the social and ethical implications of your products, signals to potential employees that your company is interested in more than the bottom line.

- Sustainability: Maybe the most valuable aspect of ethical tech is that it is sustainable. First of all, ethical concerns are a major driver of legislation, so being ethical means being ahead of the curve and preventing disruption to your business. Similarly, it provides a solid foundation on which to build your company without worrying about attracting unwanted media attention, employee walk-outs or social media boycott campaigns.

\section{Vuyiswa $M^{\prime}$ Cwabeni}

\section{SVP, Technology and Innovation at SAP SE}

Just imagine a world where we as a society could not profit from merits of inventions like the steam engine, medical treatments or the internet. The world, as we know today, would be impossible.

None of the mentioned technologies are ethical or unethical - per se. Technology is inherently neutral, and its ethical implications depend on the people developing and using it.

Ethical tech is not a new concept. But it is gaining more traction with the rise of new technologies like artificial intelligence and deep learning. The implications of these technologies force us to consider the ethics of their usage.

Imagine banks do not just have financial benchmarks in mind when they invest funds, but also make ethical considerations. Imagine purchasing departments that can add an ethical dimension to their supply chain operations. Both scenarios in turn will enable these organisations to deliver ethical services to their customers while at the same time transforming the corporate behavior.

At the same time, ethical tech can also play a differentiating factor in engineering. One of the most demanding challenges in the development of autonomous vehicles are the ethical questions that arise with this technology, eg the 'trolley problem'. The company that solves these issues first will have a significant advantage over its competitors. Indeed, ethical tech in business may lead to a 'winner takes all' scenario in which a company that 'solves' a particular ethical issue within a given market establishes a dominant position. 